\title{
Structural and Electrical Properties of Graphite Platelet Films Deposited on Low-Density Polyethylene Substrate ${ }^{+}$
}

\author{
Angela Longo 1, Mariano Palomba 1,* , Francesca Urban 2,3, Antonio Di Bartolomeo 2,3, Andrea Sorrentino ${ }^{\text {, }}$ \\ Gianni Barucca ${ }^{4}$, Giuseppina Ambrosone ${ }^{5}$, Ubaldo Coscia ${ }^{5}$ and Gianfranco Carotenuto ${ }^{1}$ \\ 1 Institute for Polymers, Composites and Biomaterials-National Research Council (IPCB-CNR), \\ SS Napoli/Portici, Piazzale E. Fermi, 1. 80055 Naples, Italy; angela.longo@cnr.it (A.L.); \\ andrea.sorrentino@cnr.it (A.S.); gianfranco.carotenuto@cnr.it (G.C.) \\ 2 Department of Physics 'E.R.Caianello', University of Salerno, Via Giovanni Paolo II 132, 84084 Salerno, Italy; \\ furban@unisa.it (F.U.); adibartolomeo@unisa.it (A.D.B.) \\ 3 Superconducting and Other Innovative Materials and Devices Institute-National Research Council \\ (SPIN-CNR), Via Giovanni Paolo II 132, 84084 Fisciano (SA), Italy \\ 4 Department SIMAU, Polytechnic University of Marche, Via Brecce Bianche I, 60131 Ancona, Italy; \\ g.barucca@univpm.it \\ 5 Department of Physics 'Ettore Pancini', University of Naples 'Federico II', Via Cintia, I, 80126 Napoli, Italy; \\ giuseppina.ambrosone@unina.it (G.A.); ubaldo.coscia@unina.it (U.C.) \\ * Correspondence: mariano.palomba@cnr.it \\ + Presented at the 2nd International Online-Conference on Nanomaterials, 15-30 November 2020; Available \\ online: https://iocn2020.sciforum.net/.
}

Citation: Longo, A.; Palomba, M.;

Urban, F.; Di Bartolomeo, A.;

Sorrentino, A.; Barucca, G.

Ambrosone, G.; Coscia, U.; Carotenuto, G. Structural and Electrical Properties of Graphite Platelet Films Deposited on Low-Density Polyethylene Substrate.

Mater. Proc. 2021, 4, 38. https://

doi.org/10.3390/IOCN2020-07917

Academic Editors: Ana María

Díez-Pascual and Guanying Chen

Published: 11 November 2020

Publisher's Note: MDPI stays neutral with regard to jurisdictional claims in published maps and institutional affiliations.

Copyright: $\odot 2020$ by the authors. Licensee MDPI, Basel, Switzerland. This article is an open access article distributed under the terms and conditions of the Creative Commons Attribution (CC BY) license (http://creativecommons.org/licenses /by/4.0/).
Abstract: Uniform conductive films composed of graphite platelets (GPs) were obtained by spraying a commercial graphite lacquer on low-density polyethylene (LDPE) substrates. According to the scanning electron microscopy investigation and X-ray diffraction analysis, the deposited films are composed of crystalline graphite platelets with an average size of $13.6 \mathrm{~nm}$. The thermoresistive behavior of the GP film on LDPE samples was investigated from 20 to $120^{\circ} \mathrm{C}$. The resistance of the samples increases considerably in the $20-100{ }^{\circ} \mathrm{C}$ range and decreases sharply for temperatures above $100{ }^{\circ} \mathrm{C}$. This behavior could be ascribed to the thermal properties of the polymer substrate. Results show that promising materials for thermoresistive applications in flexible electronics can be obtained by combining dielectric polymeric substrates with coatings based on graphite platelets.

Keywords: low-density polyethylene; graphite platelets; spray technique; coating; electrical properties

\section{Introduction}

The unique physicochemical characteristics of graphene, such as its light weight, optical transparency, flexibility, high electrical conductivity, and biocompatibility, make this material of fundamental importance in many applications [1]. Graphene has become very attractive in flexible and wearable electronics for the fabrication of sensors, actuators, and other types of electronic devices [2,3]. Nowadays, the production of large-surface graphene sheets is difficult and quite expensive, and this aspect represents an obstacle for using this material for mass productions. Graphite platelet (GP) materials are low-cost alternatives to graphene, capable of assuring moderately good mechanical, electrical, and thermal properties. Despite the small dimensions, GPs can be deposited on suitable substrates to form large-area conductive surfaces [4]. However, a uniform deposition with adequate mechanical resistance is not a simple task. It strongly depends on the chemical and physical properties of the substrate [5-9]. Polymer films can be advantageously selected as substrates for both graphene and graphite layers [10-14]. 
Here, GP films were deposited by spraying a graphite lacquer on low-density polyethylene (LDPE) substrates. Morphological and structural characterizations of the deposited films were carried out by scanning electron microscopy (SEM) and X-ray diffraction (XRD), respectively. Electrical resistance measurements of GP films on LDPE substrates were performed as a function of temperature in the $20-120^{\circ} \mathrm{C}$ range.

\section{Materials and Methods}

Large-area coatings of graphite-based materials were deposited on LDPE substrates $\left(20 \times 30 \mathrm{~cm}^{2}\right)$ by spray coating technology, using a commercial lacquer, Graphit 33 (from Kontakt Chemie, Zele, Belgium), which is commonly used for optical and electrical applications. During spraying, the full cone jet spot was horizontally directed on the film, taking a distance of $20 \mathrm{~cm}$. After spraying, the coated substrates were dried in air at room temperature, for $4 \mathrm{~h}$. In order to investigate the morphological and structural properties of the samples, scanning electron microscopy (SEM) was performed using an FEI Quanta 200 FEG microscope and X-ray diffraction (XRD) measurements were carried out by a Panalytical, X'PERT PRO diffractometer with a Cu-K $\alpha$ radiation source $(\lambda=1.5406 \AA)$. Electrical properties were studied by means of measurements under vacuum (about 2 mbar) in a coplanar configuration by silver paint contacts $(1 \mathrm{~cm}$ long and $1 \mathrm{~mm}$ spaced) spread on the top sample surfaces. Vacuum was applied to prevent possible effects of moisture or other adsorbates. Current-voltage (I-V) characteristics were taken in a Janis Research ST-500 probe station, equipped with 4 micromanipulators connected to a sourcemeasurement unit (SMU), Keithley 4200-SCS (Tektronix, Inc., Beaverton, OR, USA). The electrical resistance, $\mathrm{R}$, of the samples at different temperatures, $\mathrm{T}$, was measured during heating runs from 20 to $120^{\circ} \mathrm{C}$ at a rate of about $5{ }^{\circ} \mathrm{C} / \mathrm{min}$. The mean values of resistance were estimated by monitoring $\mathrm{R}$ on a period of $60 \mathrm{~s}$.

\section{Results and Discussion}

SEM micrographs in Figure 1 show that the coating obtained by spraying the Graphit 33 lacquer on the LDPE substrate is quite rough, porous, and made of small platelets well connected together.
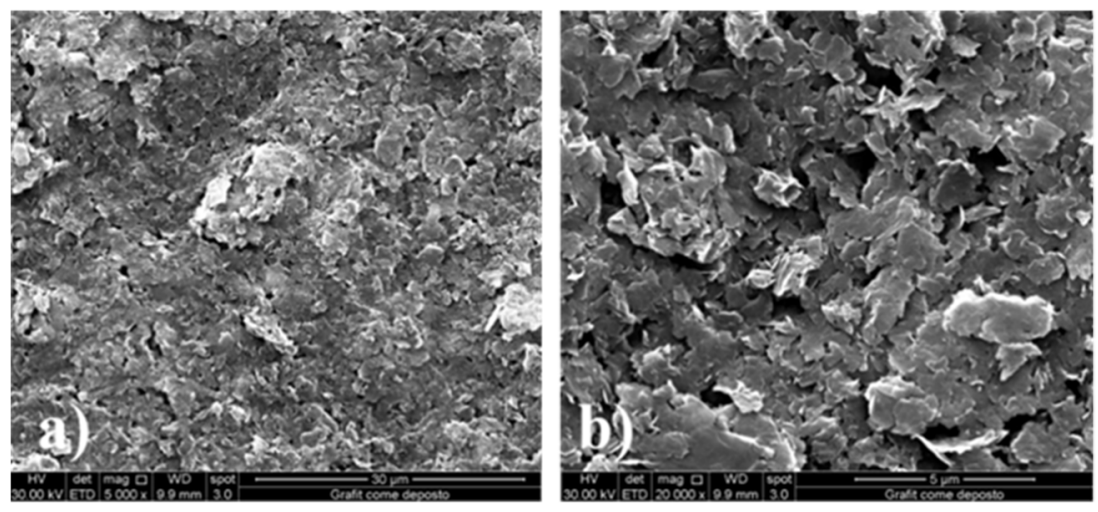

Figure 1. SEM micrographs of the "as-deposited" coating after spraying Graphit33 lacquer on lowdensity polyethylene (LDPE).

The XRD diffractogram of a typical film deposited on LDPE is given in Figure 2. This XRD measurement includes four peaks. In particular, the three peaks at $21.78^{\circ}, 24.05^{\circ}$, and $36.47^{\circ}$ belong to the crystalline phase of the LDPE substrate [15] (these peaks are overlapped to a diffuse halo, coming from the amorphous phase in the LDPE substrate) and the (002) diffraction peak located at about $26.74^{\circ}$ is due to the crystalline graphite platelets [16]. 


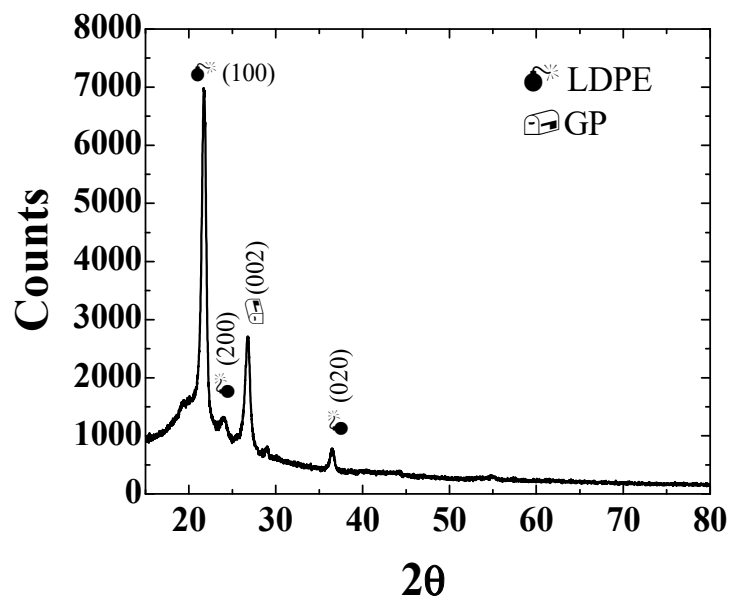

Figure 2. XRD diffractogram of graphite platelet (GP) film on LDPE.

The average size of graphite crystals was determined from the broadening of the (002) graphite diffraction peak by using Scherrer's equation [17]:

$$
\mathrm{D}=\mathrm{k} \frac{\lambda}{\mathrm{FWHM} \cos \theta}
$$

where $\mathrm{D}$ is the average size of the ordered (crystalline) domains, $\mathrm{k}$ is a dimensionless shape factor, with a value close to unity, $\lambda$ is the $\mathrm{X}$-ray wavelength $(\mathrm{Cu}-\mathrm{k} \alpha=1.54 \AA$ ), FWHM is the line broadening at half maximum intensity, and $\theta$ is the Bragg angle. An average size of $13.6 \mathrm{~nm}$ was obtained by using 0.9 as the shape factor.

Electrical measurements of GP samples were carried out under vacuum in a twoprobe configuration. In Figure 3, the current, I, of a representative sample is plotted vs. the applied voltage, $\mathrm{V}$, at the temperature of $20^{\circ} \mathrm{C}$. The linearity of the I-V characteristic indicates ohmic contacts. The resistance value, $\mathrm{R}_{0}=(164.00 \pm 0.03) \mathrm{ohm}$, was obtained by the best fit of the experimental data, with a correlation coefficient $r=1$.

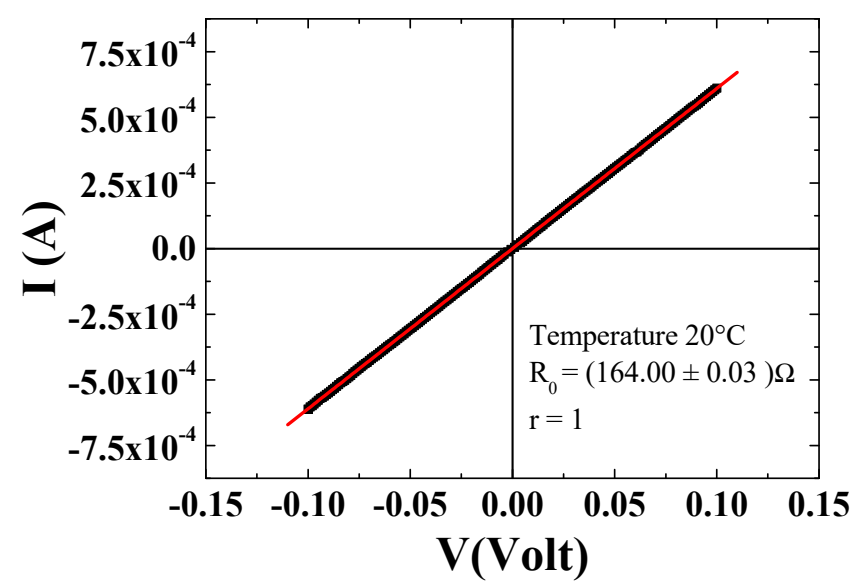

Figure 3. I-V characteristic of a GP film on LDPE substrate. The straight line is a line of best fit of the experimental data.

The thermoresistive properties of GP films were investigated by recording the resistance values, $\mathrm{R}$, during heating runs from 20 to $120{ }^{\circ} \mathrm{C}$. In Figure 4, the resistance change of the sample, shown as the R/R0 ratio, is plotted vs. temperature, T. A large nonlinear increase in the resistance can be observed in the $20-100{ }^{\circ} \mathrm{C}$ range and this behavior is opposed to that of the graphite material, whose resistance decreases with increasing temperature $[18,19]$. The resistance increase in GP films on LDPE could be ascribed to the 
thermal expansion of the polymer substrate [20,21], since the coefficient of linear thermal expansion around room temperature $\left(1-2 \times 10^{-4}{ }^{\circ} \mathrm{C}^{-1}\right)$ is more than one order of magnitude greater than that of graphite $\left(4-8 \times 10^{-6}{ }^{\circ} \mathrm{C}^{-1}\right)$ and it increases about one order of magnitude close to $100{ }^{\circ} \mathrm{C}$. The larger thermal expansion of the substrate could induce strains in the deposited graphitic film, leading to the reduction in the contact area of the platelets, with a decrease in the number of conduction paths and the consequent increase in the film resistance.

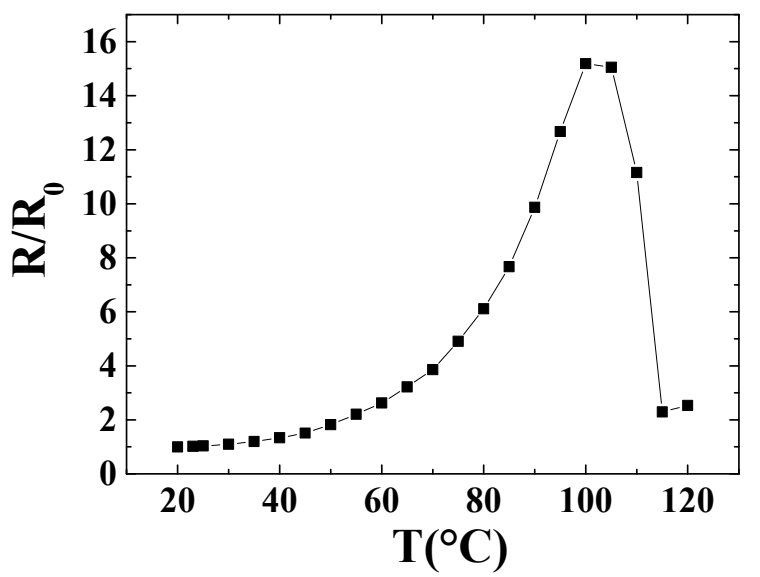

Figure 4. R/Ro vs. temperature for a GP film on LDPE substrate.

For temperatures higher than $100{ }^{\circ} \mathrm{C}$, the resistance suddenly decreases despite the continuous increase in thermal expansion. Probably, the melting and the resulting sharp decrease in the mechanical modulus of the LDPE could favor the slipping of the graphite platelets with the restoration of the conductive network on the sample surfaces. A similar temperature dependence of the electrical conductivity was observed in the LDPE filled with carbon black and carbon fiber composites [22]. The significant thermoresistive response of the investigated GP films on LDPE makes these systems suitable as temperature sensors and self-switching components in flexible electronics.

\section{Conclusions}

Large-area GP films were deposited on LDPE substrates by a spray coating technology, using a graphite lacquer. SEM images and XRD analysis show that the films consist of overlapped graphite platelets composed of crystallites with an average size of $13.6 \mathrm{~nm}$ in the (002) direction. The electrical characterization of the samples, as a function of temperature, suggests that the thermal properties of the LDPE substrate (thermal expansion and phase transition) strongly affect the thermoresistive properties of GP films. The resistance of the GP film on LDPE considerably increases in the $20-100{ }^{\circ} \mathrm{C}$ range but sharply decreases above the temperature of $100{ }^{\circ} \mathrm{C}$. The investigated material could be used as a temperature sensor in the thermal ranges where the polymeric substrate still remains solid.

Author Contributions: “Conceptualization, U.C., G.C., and A.D.B.; methodology, G.C.; validation, U.C., G.C., and A.D.B.; formal analysis, G.C., A.L., M.P., F.U., G.B., G.A, and A.S.; investigation, G.C., A.L., M.P., F.U., G.B., G.A., A.S.; data curation, A.L., M.P., F.U., and A.S.; writing-original draft preparation, G.C., A.L., and M.P.; writing - review and editing, G.C., A.L., M.P., U.C., and A.D.B.; visualization, G.A.; supervision, G.C., U.C., and A.D.B. All authors have read and agreed to the published version of the manuscript.

Funding: This research received no external funding. 


\begin{abstract}
Acknowledgments: The authors kindly acknowledge the CNR project titled "Nanocompositi polimerici per applicazione ottiche". The authors are grateful to Maria Cristina Del Barone of LAMEST laboratory (IPCB-CNR) for SEM/EDS measurements. The authors are also grateful to A. Vanzanella and the electronic workshop of INFN Napoli for the fruitful discussions and their support during the assembling of the experimental setup.
\end{abstract}

Conflicts of Interest: The authors declare no conflict of interest.

\title{
References
}

1. Warner, J.H.; Schaffel, F.; Rummeli, M.; Bachmatiuk. A. Graphene: Fundamentals and Emergent Applications; Elsevier: Oxford, UK, 2013.

2. Stoppa, M.; Chiolerio, A. Wearable electronics and smart textiles: A critical review. Sensors 2014, 14, 11957-11992.

3. Singh, T.B.; Sariciftci, N.S. Progress in plastic electronic devices. Annu. Rev. Mater. Res. 2006, 36, 199-230.

4. Cataldi, P.; Athanassiou, A.; Bayer, I.S. Graphene Nanoplatelets-Based Advanced Materials and Recent Progress in Sustainable Applications. Appl. Sci. 2018, 8, 1438.

5. Kondratov, A.P.; Zueva, A.M.; Varakin, R.S.; I.P.; Taranec, I.A. Savenkova, Polymer film strain gauges for measuring large elongations. IOP Conf. Ser. Mater. Sci. Eng. 2018, 312, 012013.

6. Huang, X.; Leng, T.; Zhang, X.; Chen, J.C.; Chang, K.H.; Geim, A.K.; Novoselov, K.S.; Hu, Z. Binder-free highly conductive graphene laminate for low cost printed radio frequency applications. Appl. Phys. Lett. 2015, 106, 203105.

7. Longo, A.; Verucchi, R.; Aversa, L.; Tatti, R.; Ambrosio, A.; Orabona, E.; Coscia, U.; Carotenuto, G.; Maddalena, P. Graphene oxide prepared by graphene nanoplatelets and reduced by laser treatment. Nanotechnology 2017, $28,224002$.

8. Bonavolontà, C.; Camerlingo, C.; Carotenuto, G.; De Nicola, S.; Longo, A.; Meola, C.; Boccardi, S.; Palomba, M.; Pepe, G.P.; Valentino, M. Characterization of piezoresistive properties of graphene-supported polymer coating for strain sensor applications. Sens. Actuators A Phys. 2016, 252, 26-34.

9. De Castro, R.K.; Araujo, J.R.; Valaski, R.; Costa, L.O.O.; Archanjo, B.S.; Fragneaud, B.; Cremona, M.; Achete, C. New transfer method of CVD-grown graphene using a flexible, transparent and conductive polyaniline-rubber thin film for organic electronic applications. Chem. Eng. J. 2015, 273, 509-518.

10. Palomba, M.; Longo, A.; Carotenuto, G.; Coscia, U.; Ambrosone, G.; Rusciano, G.; Nenna, G.; Barucca, G.; Longobardo, L. Optical and electrical characterizations of graphene nanoplatelet coatings on low density polyethylene. J. Vac. Sci. Technol. B 2018, 36, 01A104.

11. Coscia, U.; Palomba, M.; Ambrosone, G.; Barucca, G.; Cabibbo, M.; Mengucci, P.; de Asmundis, R.; Carotenuto, G. A new micromechanical approach for the preparation of graphene nanoplatelets deposited on polyethylene. Nanotechnology 2017, 28, 194001.

12. Fechine, G.J.M.; Martin-Fernandez, I.; Yiapanis, G.; Bentini, R.; Kulkarni, E.S.; De Oliveira, R.V.B.; Hu, X.; Yarovsky, I.; Neto, A.H.C.; Ozyilmaz, B. Direct dry transfer of chemical vapor deposition graphene to polymeric substrates. Carbon 2015, 83, 224231.

13. Martins, L.G.P.; Song, Y.; Zeng, T.; Dresselhaus, M.S.; Kong, J.; Araujo, P.T. Direct transfer of graphene onto flexible substrates PNAS 2013, 110, 17762-17767.

14. Tian, M.; Huang, Y.; Wang, W.; Li, R.; Liu, P.; Liu, C.; Zhang, Y. Temperature-dependent electrical properties of graphene nanoplatelets film dropped on flexible substrates. J. Mater. Res. 2014, 29, 1288-1294.

15. Murray, K.A.; Kennedy, J.E.; McEvoy, B.; Vrain, O.; Ryan, D.; Cowman, R.; Higginbothama, C.L. Characterisation of the Surface and Structural Properties of Gamma Ray and Electron Beam Irradiated Low Density Polyethylene. Int. J. Mat. Sci. 2013, 3, 1-8.

16. Johra, F.T.; Lee, J.-W.; Jung, W-G. Facile and safe graphene preparation on solution-based platform. J. Ind. Eng. Chem. 2014, 20, 2883-2887.

17. Klug, H.P.; Alexander, L.E. X-ray Diffraction Procedures for Polycrystalline and Amorphous Materials, 2nd ed.; Wiley: New York, NY, USA, 1974.

18. Dinh, T.; Phan, H.-P.; Qamar, A.; Woodfield, P.; Nguyen, N.-T.; Dao, D.V. Thermoresistive effectfor advanced thermal sensor: Fundamentals, design consideration and application. J. Microelectromech. Syst. 2017, 26, 966-986.

19. Iwashita, N.; Imagawa, H.; Nishiumi, W. Variation of temperature dependence of electrical resistivity with crystal structure of artificial graphite products. Carbon Am. Carbon Commit. 2013, 61, 602-608.

20. Palomba, M.; Carotenuto, G.; Longo, A.; Sorrentino, A.; Di Bartolomeo, A.; Iemmo, L.; Urban, F.; Giubileo, F.; Barucca, G.; Rovere, M.; et al. Thermoresistive Properties of Graphite Platelet Films Supported by Different Substrates. Materials 2019, 12, 21.

21. Di Bartolomeo, A.; Iemmo, L.; Urban, F.; Palomba, M.; Carotenuto, G.; Longo, A.; Sorrentino, A.; Giubileo, F.; Barucca, G.; Rovere, M.; et al. Graphite platelet films deposited by spray technique on low density polyethylene substrates. Mater. Today Proc. 2020, 20, 87-90.

22. Di, W.; Zhang, G.; Xu, J.; Peng, Y.; Wang, X.; Xie, Z. Positive temperature coefficient/negative temperature coefficient effect of Low density polyethylene filled with a mixture of carbon black and carbon filler. J. Polym. Sci. Part B Polym. Phys. 2003, 41, 30943101. 